\title{
Experimental Study on a Novel Solar Watering Tube for Producing Water from the Air
}

\author{
Hui-Zhong ZHAO ${ }^{* 1,2, a}$ and Jun-Feng CHENG $^{1, b}$ \\ 1 Merchant Marine College, Shanghai Maritime University, Shanghai 201306, P.R. China \\ 2 Department of Mechanical Engineering at the State University of New York at Stony Brook USA \\ aemail: hzzhao@shmtu.edu.cn, bemail: 478895422@qq.com \\ ${ }^{*}$ Corresponding author
}

Keywords: Solar energy; Solar watering tube; Fresh water; Humid air; Compound adsorbent; Absorption/Desorption

\begin{abstract}
In this paper, one novel solar adsorption watering tube was designed. Solar watering tube (SWT) is an independent unit producing water from air, which uses solar energy to drive the production process. Compared with the traditional methods of producing water, the production process of SWT bases on adsorption/desorption theory. The influence of operating conditions on the SWT was investigated. Under the typical weather conditions, as follows, the ambient temperature was about $20^{\circ} \mathrm{C} \sim 35^{\circ} \mathrm{C}$, ambient relative humidity was about $44 \% \sim 74 \%$, and the solar radiation was about 22MJ.d-1m-2, the adsorbent bed temperature could reach $222^{\circ} \mathrm{C}$ in the day and cooled down to about $40^{\circ} \mathrm{C}$ in the night. A single SWT could produce about $90 \mathrm{ml}$ water one day.
\end{abstract}

\section{Introduction}

Solar energy is the source of energy for people and modern society. Solar energy is one of the best renewable sources, it is clean and environment friendly. The earth is covered by large volumes of water; however, there are lots of dry regions lacks of water. The problem of providing dry areas with fresh water can be solved by the following methods [1]:

1. Transportation of water from other locations;

2. Desalination of saline water;

3. Extraction of water from atmospheric air.

Transportation of water to these regions is usually very expensive, and desalination depends on the presence of saline water resources which are usually rare in dry regions. It is well-known that the global air is a huge and renewable water source which contains about 14,000 $\mathrm{km}^{3}$ [2] of water vapor. Many regions are deficient in fresh water, so the extraction of water from the air may be a novel way of producing fresh water in dry areas.

The use of solar energy for adsorption refrigeration and producing fresh water is one of the hot issues in research in recent years, and scholars from all countries are studying deeply about it. $\mathrm{N}$. Audah studied the feasibility of using a solar-powered liquid desiccant system to meet both building cooling and fresh water needs in Beirut's humid climate, using parabolic solar concentrators as a heat source for regenerating the liquid desiccant. In the Lebanon coastal climate with conditioned area of $80 \mathrm{~m}^{2}$, the objective was to produce 15L of fresh drinking water a day and meet air conditioning need of residence at minimum energy cost [3]. Efat Chafik presented a new water desalination process. The basic unit operation in this process was to use solar energy for heating an air stream, and seawater was added into the hot air in order to humidify it. On the base of this solar desalination process, a desalination plant was predicted to provide $10 \mathrm{~m}^{3}$ of potable water daily [4]. Ahmed Sultan suggested a non-conventional method for water production from atmospheric air on a 24-h basis, using a compact system. They concluded that the maximum efficiency increased with the initial concentration and decreased with the increase of the regeneration air stream velocity and absorption temperature [5]. H.I. Abualhamayel used a suitable liquid desiccant to extract fresh water from the humid atmosphere in Dhahran, Saudi Arabia, and they showed that for given operating 
conditions it was possible to obtain about $1.92 \mathrm{~kg}$ of water per $\mathrm{m}^{2}$ of the unit [6]. Chou analyzed thermal characteristics of the apparatus for producing drinking water from air using both adsorbents and beat pump by solar energy and calculated the efficiencies of producing drinking water [7-9]. Liu proposed a new composite adsorbent $\mathrm{Si}_{2} \cdot \mathrm{xH}_{2} \mathrm{O} \cdot \mathrm{yCaC} 1_{2}$ and made a portable unit for extracting water from air. The experimental results showed that the equilibrium adsorbent uptake was 1.9 times that of synthetic zeolite $13 \mathrm{X}$ (13X zeolite molecular sieves). The water adsorbed in the adsorbent bed could be desorbed at $60-80{ }^{\circ} \mathrm{C}$, and it could be driven by solar energy [10, 11].

Therefore, this work presents a novel unit of SWT. Different from the Solar Cooling Tube (SCT) [12-15] which uses solar energy for adsorption refrigeration and getting cooling capacity, the SWT can produce liquid $\mathrm{H}_{2} \mathrm{O}$ from air using solar energy as power. In this paper, the SWT was experimentally studied, and the apparatus consists of an adsorbent bed, a condenser, a water collector and a hard borosilicate glass tube.

\section{Principle}

Based on the adsorption/desorption theory, the SWT adsorbs vapour from air in the night and uses solar energy to heat adsorbent bed which desorbs vapour in the day. Using the compound adsorbent bed, the temperature difference between day and night corresponds to the adsorption capability difference of adsorbent bed. The SWT produces fresh water from air.

The sketch and the photograph of adsorption and desorption process of the SWT is shown in Fig. 1. The length of the solar watering tube is $1800 \mathrm{~mm}$. the Diameter of the outer tube and inner tube is $58 \mathrm{~mm}$ and $47 \mathrm{~mm}$ respectively, and the effective surface area is about $0.0846 \mathrm{~m}^{2}$. This SWT is mainly composed with these parts: vacuum tube, adsorbent bed, condenser, $\mathrm{H}_{2} \mathrm{O}$ vapors channel, airproof plug, and water bottle. The vacuum tube is made of hard borosilicate glass and has high transmission of sunlight, and it also can sustain high degree of vacuum (lower than $5 \times 10^{-3} \mathrm{~Pa}$ ).

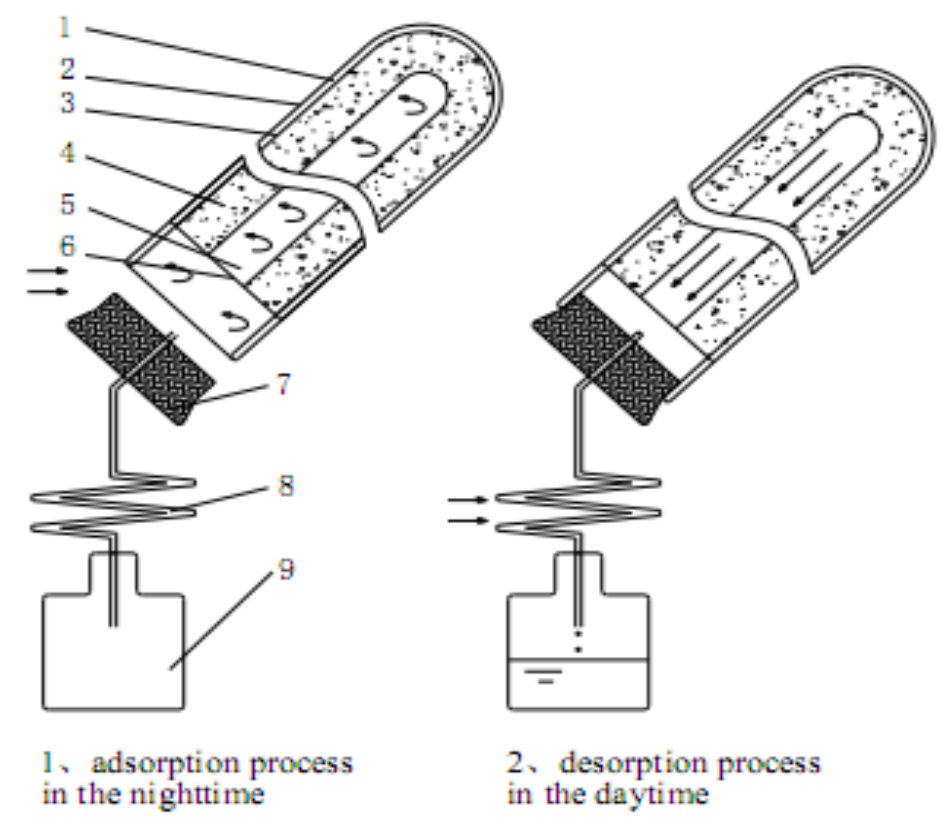




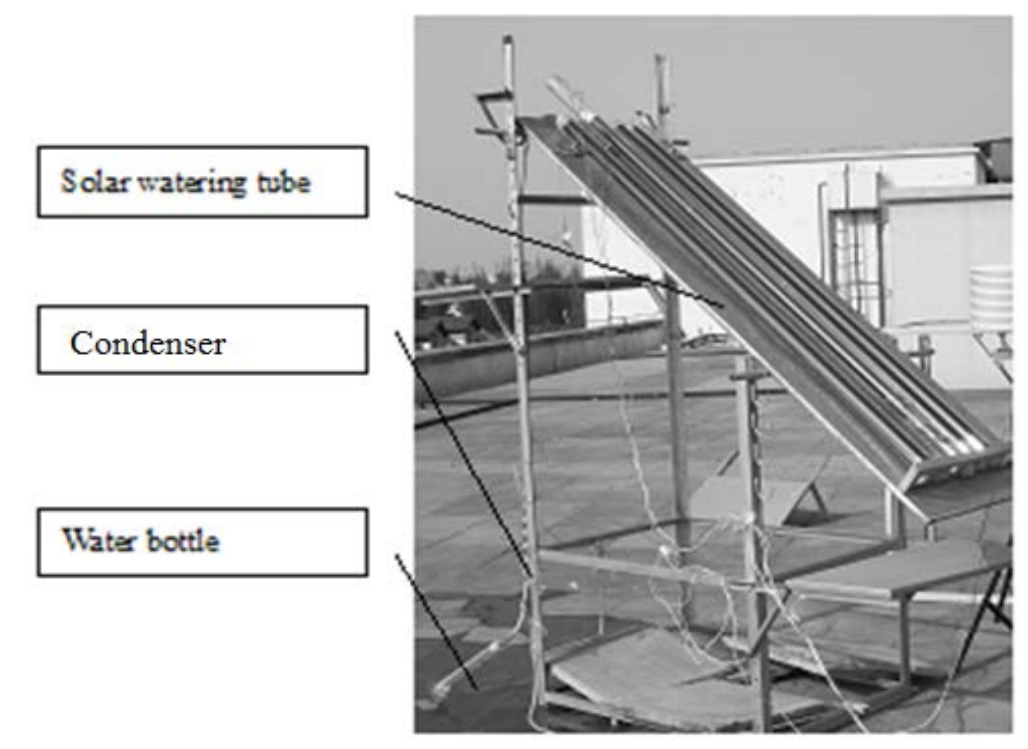

1. outer glass, 2. inner glass, 3. vacuums layer, 4. adsorbent bed, 5 . $\mathrm{H} 2 \mathrm{O}$ vapors channel, 6 filter net, 7. airproof plug, 8. condenser, 9. water bottle

Fig.1 Sketch and photograph of adsorption and desorption process of the SWT

The process of producing water from air by SWT is as following:

In the night, the moist atmosphere flows through the adsorbent bed. When the temperature drops low enough, the adsorbent bed begins to adsorb vapour from the moist atmosphere. The adsorption process lasts about 12 hours and ends in the next morning.

In the morning, the airproof plug is sealed to the vacuum tube. The adsorbent bed begins to receive solar energy, and the adsorbent temperature rises up rapidly, because the vacuum tube helps to gather solar energy with little loss. When the temperature of adsorbent bed rises high enough, the vapour desorbs from the adsorbent bed. The steam releases the latent heat during condensation, and the water is stored in the water bottle because of gravity. In the whole day, the SWT can receive solar radiation while vapour keeps desorbing from the adsorbent bed, so fresh water is produced continuously in the daytime until the solar radiation is too weak for desorption.

The main apparatuses used in the experiment of SWT performance were as following: a 2700 Multimeter / Data Acquisition system of Keithley Co. was used for collecting the data of temperature measurement, T-type thermo-couples and K-type thermo-couples were used as the temperature sensors for the lower and higher temperature testing respectively, a model TRM-123 Temperature \& Radiation Instrument produced by Jinzhou was used for measuring the solar radiation density, and a model RYQ-1 automatic surface meteorological station was used for measuring the environmental temperature and relative humidity of the air. The intervals between measuring of the temperature and solar radiation were 5 minutes, and the data could be shown instantaneously in the computer and stored in the appointed document.

\section{Results and Discussion}

\section{Ambient Temperature and Relative Humidity Variation}

The trends of ambient temperature and relative humidity variation are shown in Fig.2. The maximum and minimum ambient temperatures were about $35.2^{\circ} \mathrm{C}$ and $20.3^{\circ} \mathrm{C}$ respectively. The average ambient temperature was $25.7^{\circ} \mathrm{C}$. The ambient relative humidity fluctuates between $44 \%$ and $74 \%$ during the experimental time. 


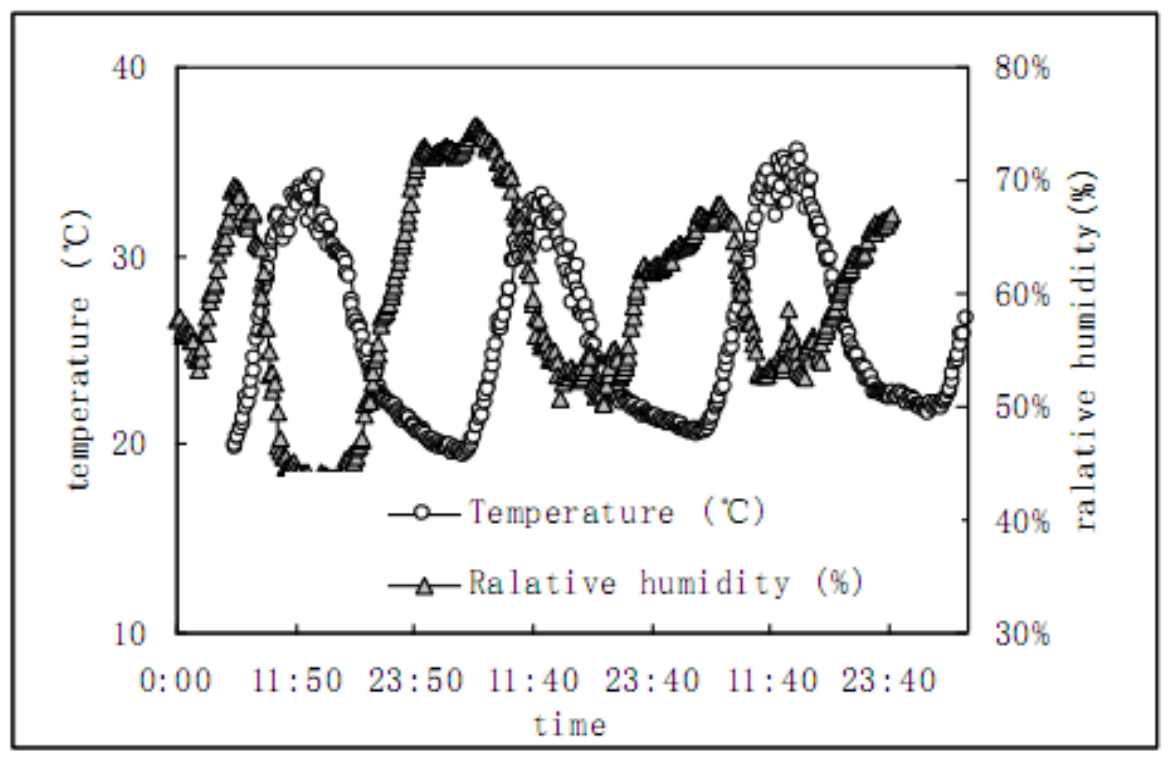

Fig.2 The ambient temperature and relative humidity

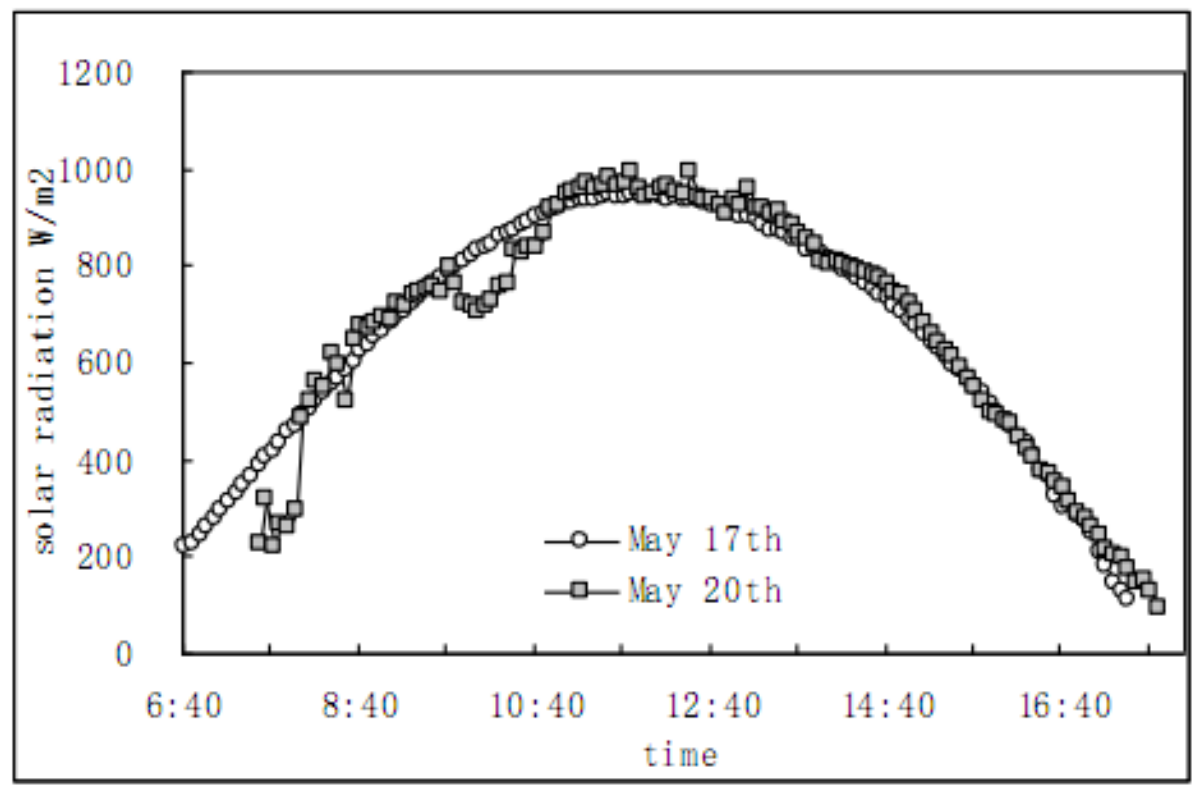

Fig. 3 Variation of solar radiation

\section{Solar Radiation Variation}

During the experimental period, the weather was sunny and a little cloudy. The solar radiation variation is shown in Fig.3. The max solar radiation was about $1000 \mathrm{~W} / \mathrm{m}^{2}$ and the minimum was about $200 \mathrm{~W} / \mathrm{m}^{2}$. The daily solar radiation from the two experiments were about $21.51 \mathrm{MJ} \cdot \mathrm{d}^{-1} \mathrm{~m}^{-2}$ and $21.87 \mathrm{MJ} \cdot \mathrm{d}^{-1} \mathrm{~m}^{-2}$ respectively.

\section{The Adsorbent Bed Temperature Variation}

The adsorbent bed temperature variation of the SWT in two cycles of adsorption is shown in Fig.4. In the day, the adsorbent bed received the solar energy. The adsorbent temperature rose up rapidly to $222^{\circ} \mathrm{C}$, and the water was desorbed from the $13 \mathrm{X}$ zeolite adsorbent bed. The vapour released the latent heat during condensation and became liquid, then stored in water bottle because of gravity.

When the adsorbent temperature dropped low enough at night, the adsorbent bed began to adsorb the water vapour from the air. In the adsorption process, the fresh air which contained water vapour flowed though the adsorbent bed and the adsorbent bed adsorbed vapour from atmosphere. The 
adsorbent bed temperature variation in the nighttime is shown in Fig.4. The adsorbent bed temperature cooled down from about $110^{\circ} \mathrm{C}$ to the minimum of about $40^{\circ} \mathrm{C}$. At this temperature the adsorbent bed can adsorb water from atmosphere.

\section{The Condensation Temperature Variation}

The condensation temperatures of the SWT were tested in this experiment. There were two temperature test positions near the inlet and outlet of the condenser. In the desorption process from 7:30 to 17:30 in the daytime, the desorbed water vapour was condensed in the condenser. In this experiment, the temperature was measured near the inlet of the condenser. The variation of the condensation temperature can be seen in Fig.5. The temperature of inlet position varied from $22.9^{\circ} \mathrm{C}$ at 7:30 am to about $32.2^{\circ} \mathrm{C}$ at $13: 45 \mathrm{pm}$, while the outlet position varied from $22.8{ }^{\circ} \mathrm{C}$ at $7: 30$ am to about $29.3^{\circ} \mathrm{C}$ at $13: 45 \mathrm{pm}$.

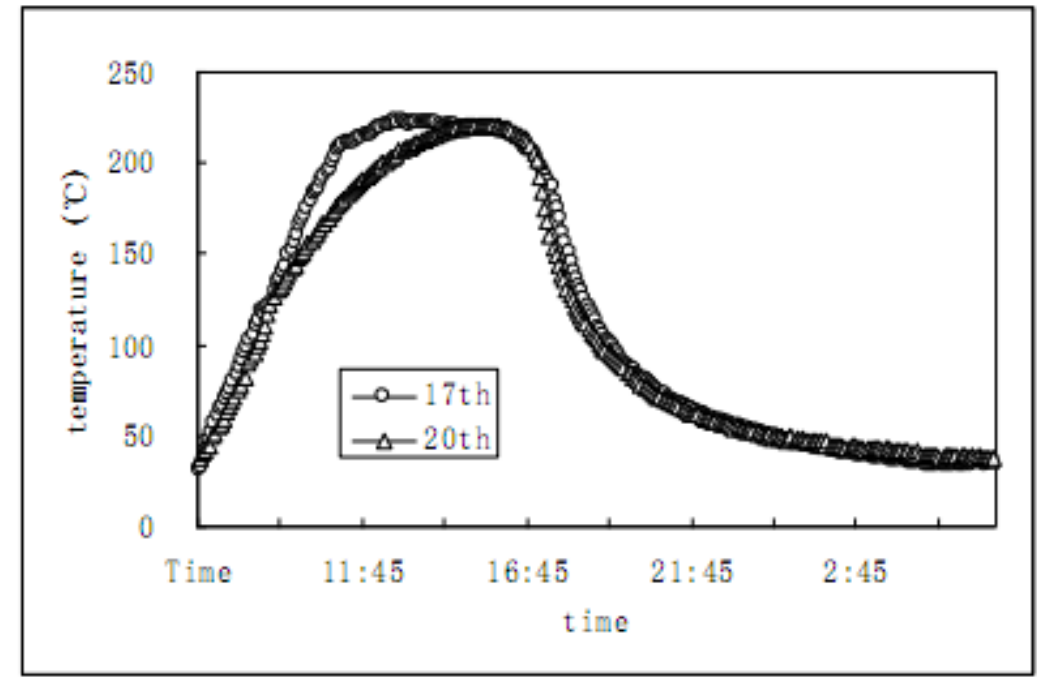

Fig.4 The adsorbent bed temperature variation of the SWT

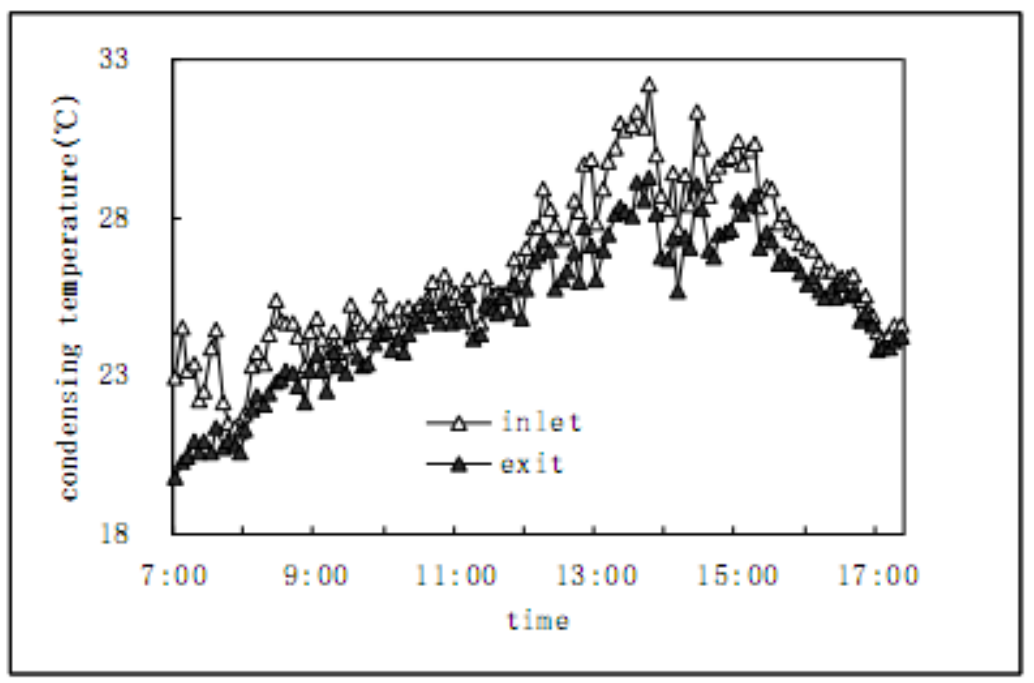

Fig.5 The inlet and exit condensation temperature variation

\section{The Fresh Water Yield of a Single SWT}

The fresh water yield of a single SWT is the characteristics to evaluate the ability of the SWT. It can be seen in Fig.6. During this experiment, fresh water yield was tested about every 30 minutes. From Fig. 6 the rate of fresh water yield during 8:00-14:00 was high and became low after 14:00. The experimental results indicate that the daily fresh water yield of a single SWT was $93 \mathrm{ml}$ and $89 \mathrm{ml}$ 
respectively. In terms of per square meter, the daily fresh water output of the system was $1099 \mathrm{ml} / \mathrm{m}^{2}$ and $1052 \mathrm{ml} / \mathrm{m}^{2}$ respectively.

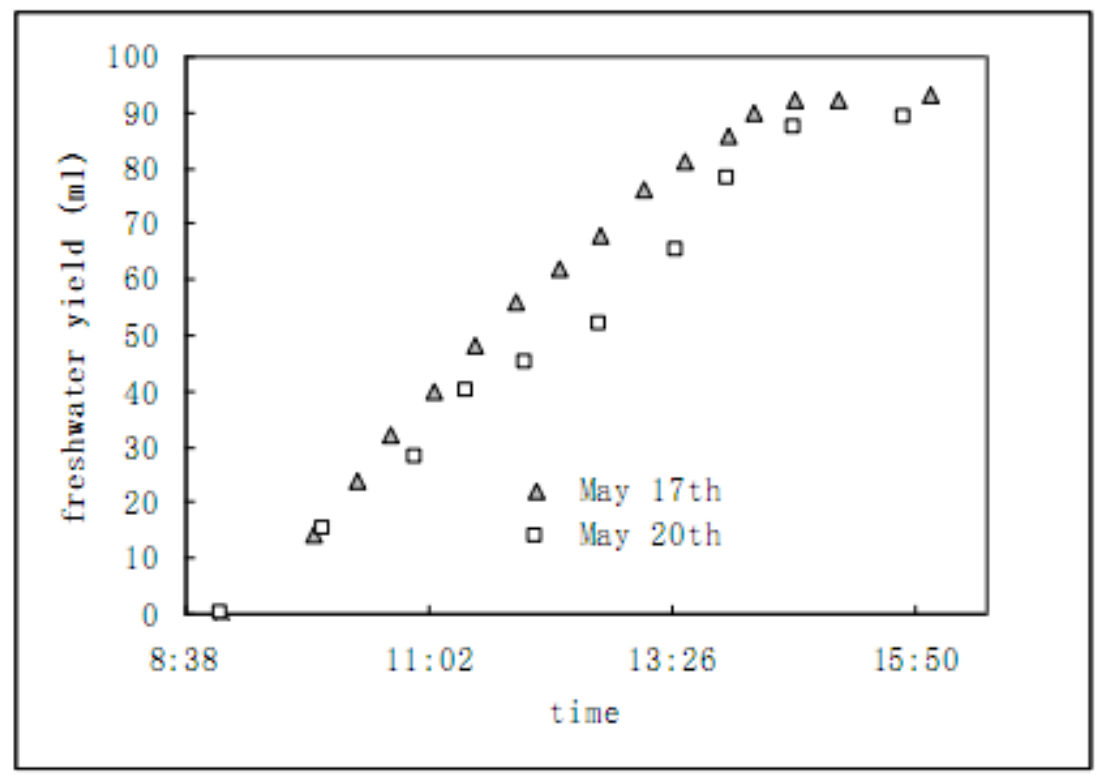

Fig.6 the fresh water yield of a single SWT

\section{Conclusions}

The SWT uses solar energy as heating resource to acquire fresh water. The performance of the SWT was experimentally studied in this research and the following conclusions could be drawn:

1. On an average day, when the ambient temperature was about $20^{\circ} \mathrm{C}-35^{\circ} \mathrm{C}$, the ambient relative humidity was about $44 \%-74 \%$ and the solar radiation was about $22 \mathrm{MJ} \cdot \mathrm{d}^{-1} \mathrm{~m}^{-2}$, the adsorbent bed temperature of the SWT could reach to $222^{\circ} \mathrm{C}$, and this temperature can reach to the standard of desorption.

2 In the night, the adsorbent bed temperature dropped from $110^{\circ} \mathrm{C}$ to the minimum of about $40^{\circ} \mathrm{C}$. $40^{\circ} \mathrm{C}$ can reach to the standard of the adsorbent bed to adsorb vapour from air.

3. The condensation temperature of the SWT varied from $22^{\circ} \mathrm{C}$ to $32^{\circ} \mathrm{C}$ during the day.

4. The daily fresh water yield of a single SWT was about $90 \mathrm{ml}$ a day. In terms of per square meter, the daily fresh water output of the system was $1050 \mathrm{ml} / \mathrm{m}^{2}$.

\section{Acknowledgements}

This work was financially supported by Innovation Program of Shanghai Municipal Education commission (Contract No. 13ZZ121) and Natural Science Foundation of China (Contract No. 50976073), the supports are gratefully acknowledged.

\section{References}

[1] H. E. Gad, A. M. Hamed, I. I. El-Sharkawy, Application of a solar desiccant/collector system for water recovery from atmospheric air, Renew Energ, 22 (2001) 541-56.

[2] J.G. Ji, R.Z. Wang, L.X. Li, New composite adsorbent for solar-driven fresh water production from the atmosphere, Desalination, 212 (2007) 176-82.

[3] N. Audah, N. Ghaddar, K. Ghali, Optimized solar-powered liquid desiccant system to supply building fresh water and cooling needs, Appl Energ, 88 (2011) 3726-36.

[4] Efat Chafik, A new type of seawater desalination plants using solar energy, Desalination, 156 (2003) 333-48. 
[5] Ahmed Sultan, Absorption/regeneration non-conventional system for water extraction from atmospheric air, Renew Energ, 29 (2004) 1515-35.

[6] H.I. Abualhamayel, P. Gandhidasan, A method of obtaining fresh water from the humid atmosphere, Desalination, 113 (1997) 5l-63.

[7] Qiaoli Chou, Jian Zong, Xinshi Ge, Yongtang Wang, Comparision of the efficiencies of producing drinking water from air between the apparatus using adsorpbents and heat pump both by solar energy, Acta enerciae solaris sinica, 17 (1996) 365-70.

[8]Qiaoli Chou, Xinshi Ge, Yaohong Shu, Yongtang Wang, The analysis of energy banlance of an apparatus producing drinking water from air using adsorbents by solar energy, Acta enerciae solaris sinica, 17 (1996) 38-43.

[9]Qiaoli Chou, Yaohong Shu, Xinshi Ge, Yong Wang, A technique of an apparatus producing drinking water from air using adsorbents by solar energy theoretical and experimental research, Acta enerciae solaris sinica, 15 (1994) 341-6.

[10]Yefeng Liu, Hongwu Fan, Ruzhu Wang, Experiment research on adsorption properties of a new composite adsorpbent with the desert climate in China to extract water from air, Ion exchanger and adsoption, 18 (2002) 440-5.

[11]Yefeng Liu, Hongwu Fan, Ruzhu Wang, Performance comparison of a new composite adsorbent $\mathrm{SiO} 2 \cdot \mathrm{xH} 2 \mathrm{O} \cdot \mathrm{yCaCl} 2$ and other common adsorbents to extract water from air, Acta enerciae solaris sinica, 24(2003)141-4.

[12] Huizhong Zhao, Min Zhang, Chen Huang, Experimental study of solar cooling tube used on building, J. Cent. South Univ. Technol, 14(2007) 235-9.

[13] Liu Z Y., Lu Y Z., Zhao J X, Zeolite-active carbon compound adsorption and its use in adsorption solar cooling tube, Sol Energ Mat Sol C, 52 (1998) 45-53.

[14] Xiaodong Ma, Zhenyan Liu, Huizhong Zhao, Development of a Solar-Powered Adsorption Cooling Tube, Energ Fuel, 21 (2007) 354-60.

[15] Huizhong Zhao, Min Zhang, Zhenyan Liu, Mechanical and experimental study on freeze proof solar powered adsorption cooling tube using active carbon/methanol working pair, Energ Convers Manage, 49 (2008) 2434-8. 